EESTI NSV TEADUSTE AKADEEMIA TOIMETISED. 30. KOIDE GEOLOOGIA. 1981, NR. 1

ИЗВЕСТИЯ АКАДЕМИИ НАУК ЭСТОНСКОП ССР. ТОМ 30 ГЕОЛОГИЯ. 1981, № 1

Лейли СААРСЕ, $\overline{|Б . ~ В Н М Б А|, ~ Р . ~ С Н Н Н С А Л У, ~}$ Д. ТРУКСНЕ, В. ШКЕЛЕ

\title{
АГРОХИМИЧЕСКАЯ ХАРАКТЕРИСТИКА САПРОПЕЛЕЙ МАЛЫХ ОЗЕР ЭСТОНИИ
}

Актуальной задачей сельского хозяйства является повышение плодородия почв и урожаев сельскохозяйственных культур. Сельское хозяйство издавна знает многие приемы и мероприятия, в том числе и употребление сапропелей в качестве органо-минерального удобрения с целью повышения плодородия почв. Так как состав и свойства сапропелей отдельных водоемов значительно отличаются и различным образом влияют на свойства почв, то их целенаправленное изучение является весьма важным.

Изучение агрохимических свойств эстонских сапропелей началось в 60-е гг. (Veber, 1967, 1970 и др.) и продолжается в Институте геологии АН ЭССР в содружестве с кафедрой химии Латвийской сельскохозяйственной академии и в настоящее время (Вимба и др., 1978). Образцы сапропелей для данной работы были отобраны из озер, располагающихся в разных физико-географических и почвенных районах республики (рисунок). Из всех озер для анализа брали средние пробы, характеризующие всю сапропелевую толщу. Из озера Юлемисте были отобраны три пробы: $M_{4}$ - из северной, $\mathrm{VII}_{6}$ - из средней и $\mathrm{VIII}_{6}$ из юго-западной части озера. Пункты взятия проб в озере Харку находились соответственно в северной $\left(\mathrm{M}_{2}\right)$ и восточной частях $\left(\mathrm{II}_{1}\right)$, в озере Кахала - в юго-западной $\left(\mathrm{I}_{1}\right)$ и северной $\left(\mathrm{II}_{9}\right)$ частях озера. Bce остальные пробы взяты со сплавин соответствующих озер.

При определении агрохимических свойств сапропелей применена методика, изложенная во многих руководствах (Агрохимические методы исследования почв, 1975; Аринушкина, 1961; Возбудцкая, 1968; Hallik, 1948 и др.).

Известно, что для жизнедеятельности растений необходим целый ряд элементов: азот, калий, фосфор, кальций, сера, железо, медь, магний, кислород, водород, марганец, бор, окись кремния, алюминий, которые не могут быть заменены другими (Качинский, 1975). Некоторые из них, как кремний, железо, алюминий, обычно имеются в почвах в достаточных количествах, а калий, фосфор, азот и микроэлементы бор, медь, марганец, иод и другие часто встречаются в недостаточном количестве и их следует добавлять в почву. Поэтому нами определялись именно эти вещества (табл. 1-4).

Реакция и кислотность сапропелей. Усвоение питательных элементов растениями во многом зависит от реакци и почвы, а также от реакции удобрения. Для характеристики реакции сапропелей использовался $\mathrm{pH}$ как в водной, так и в $\mathrm{KCl}$ вытяжке. Из этих показателей наиболее объективным считается $\mathrm{pH}_{\mathrm{KCl}}$, так как $\mathrm{pH}_{\mathrm{H}_{3} \mathrm{O}}$ может значительно изме- 


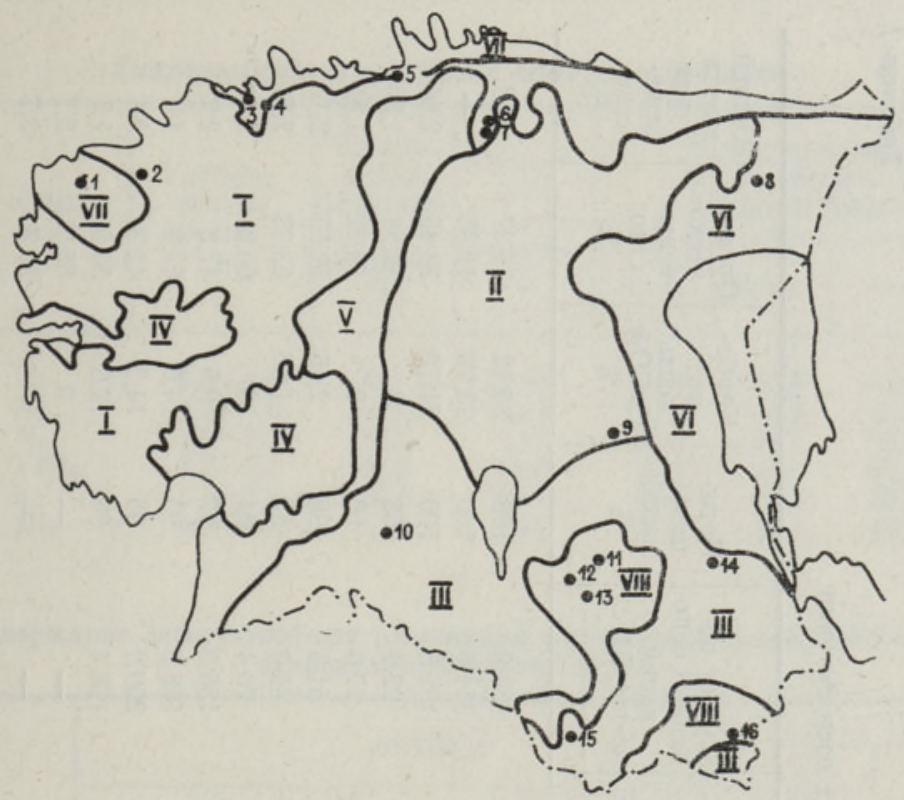

Расположение изученных озер по почвенным районам республики (Lillemaa, 1958). I - дерново-карбонатные почвы, II дерново-карбонатные выщелоченные и оподзоленные почвы, III - дерново-подзолистые почвы, IV - дерново-глеевые почвы, V - подзолистые и болотные почвы Средней Эстонин, VI - подзолистые и болотные почвы в Чудской впадине, VII - подзолистые почвы предглинтовой зоны, VIII - эрозионные дерново-подзолистые почвы. Озера: 1 - Вескиярв, 2 Руйла, 3 - Харку, 4 - Юлемисте, 5 - Кахала, 6 - Вийтна Сууръярв, 7 - Кыверъярв, 8- Мустъярв, 9- Элиствере, 10 - Пяйдре, 11 - Пангоди, 12 - Рябиярв, 13 - Юузаярв, 14 - Моосте, 15 - Кообассааре, 16 - Кирикумяэ.

няться в зависимости от температуры, микробиологических и химических условий (Hallik, 1948).

Реакция изученных нами сапропелей колеблется от кислой до слабощелочной. Принимая за основу классификацию почв по $\mathrm{pH}_{\mathrm{KCl}}$ (Hallik, 1965), изученные сапропели являются в большинстве случаев нейтральными (рН 6,5-7,0). Кислые сапропели встречаются в озерах, на водосборах которых распространяются бедные карбонатами морские пески (оз. Харку, Вескиярв). Слабощелочными (pH $7,2-7,3)$ оказались сапропели озер Элиствере и Пангоди.

Гидролити ческая кислотность характеризует потребность в кальции для нейтрализации кислой реакции. Она тесно связана с реакцией сапропелей: чем ниже значения $\mathrm{pH}$, тем выше гидролитическая кислотность и соответственно выше потребность в кальции. Высокая гидролитическая кислотность характерна для сапропелей оз. Вескиярв $(39$ мг-экв/100 г) и Харку $(11-19$ мг-экв/100 г), реакция которых кислая. Остальные изученные нами сапропели обладают нейтральной или слабощелочной реакцией и соответственно низкой гидролитической кислотностью $(0,3-9$ мг-экв/100 г; табл. 1$)$.

С тепень на сыщения - это отношение суммы обменных оснований к емкости поглощения, характеризующее насыщенность сапропелей 


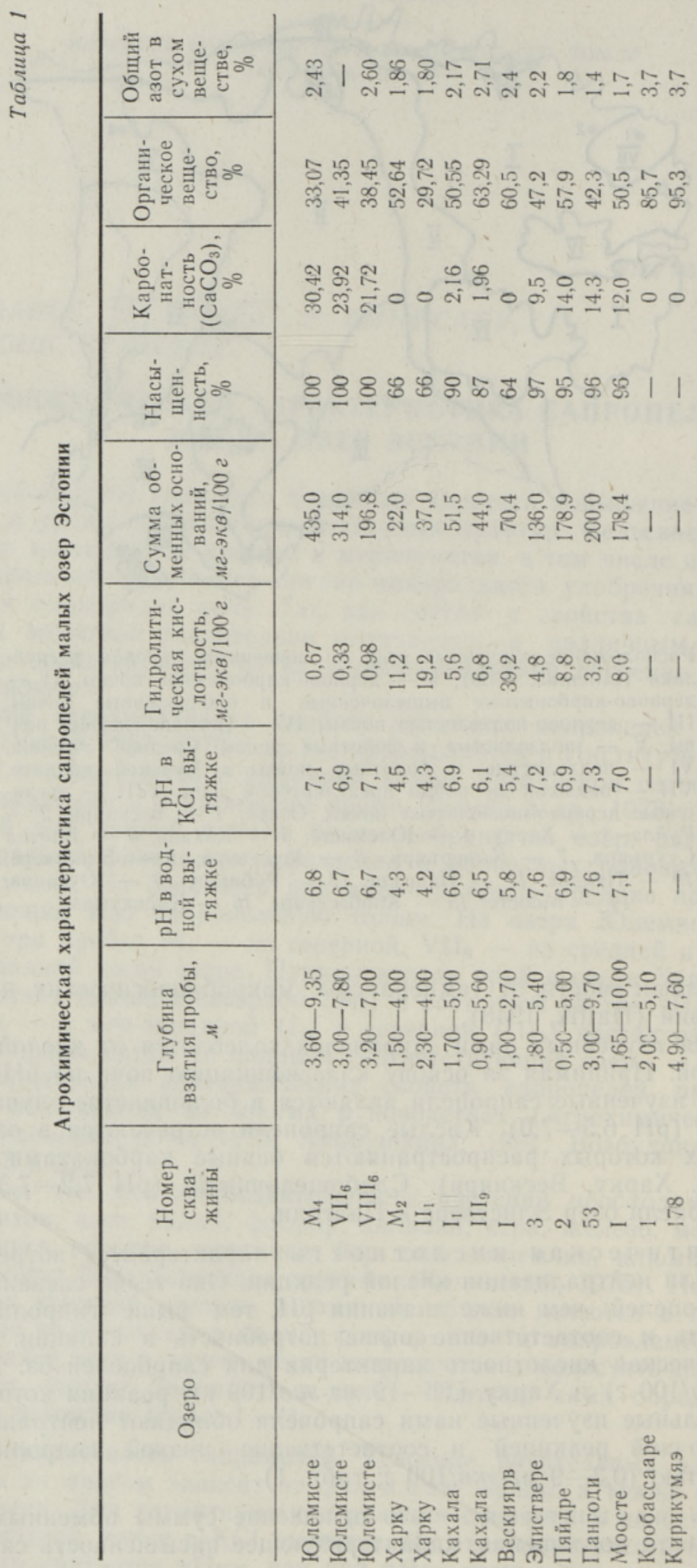


Гидролизуемость азотистых веществ сапропелей

Таблица 2

\begin{tabular}{|c|c|c|c|c|c|c|c|c|}
\hline \multirow{2}{*}{ Озеро } & \multirow{2}{*}{$\begin{array}{l}\text { Сква- } \\
\text { жина }\end{array}$} & \multirow{2}{*}{$\begin{array}{c}\text { Глубина } \\
\text { взятия } \\
\text { пробы, } \\
\mu\end{array}$} & \multirow{2}{*}{$\begin{array}{c}\text { Органи- } \\
\text { ческое } \\
\text { вещество } \\
\text { в сухом } \\
\text { веществе, } \\
\%\end{array}$} & \multirow{2}{*}{$\begin{array}{c}\text { Обший } \\
\text { азот } \\
\text { в сухом } \\
\text { вешестве, } \\
\%\end{array}$} & \multicolumn{4}{|c|}{$\begin{array}{c}\text { Гидролизуемый азот, } \\
\% \text { от общего азота / } \\
\text { концентрация } \mathrm{HCl}\end{array}$} \\
\hline & & & & & $0,1 \mathrm{н}$. & 0,5 н. & 1,0 н. & $2,0 \mathrm{H}$. \\
\hline $\begin{array}{l}\text { Харку } \\
\text { Харку } \\
\text { Юлемисте } \\
\text { Юлемисте } \\
\text { Кахала } \\
\text { Қахала }\end{array}$ & $\begin{array}{l}\mathrm{II}_{1} \\
\mathrm{M}_{2} \\
\mathrm{M}_{4} \\
\mathrm{VIII}_{6} \\
\mathrm{I}_{1} \\
\mathrm{HI}_{9}\end{array}$ & $\begin{array}{l}2,3-4,0 \\
1,5-4,0 \\
3,6-9,3 \\
3,2-7,0 \\
1,7-5,0 \\
0,9-5,6\end{array}$ & $\begin{array}{l}29,7 \\
52,6 \\
33,1 \\
41,4 \\
50,5 \\
63,3\end{array}$ & $\begin{array}{l}1,80 \\
1,86 \\
2,43 \\
2,60 \\
2,17 \\
2,711\end{array}$ & $\begin{array}{l}34,0 \\
31,2 \\
29,2 \\
22,7 \\
25,8 \\
17,3\end{array}$ & $\begin{array}{l}51,6 \\
48,9 \\
33,7 \\
37,3 \\
33,7 \\
31,4\end{array}$ & $\begin{array}{l}63,3 \\
65,5 \\
52,6 \\
53,1 \\
49,8 \\
46,2\end{array}$ & $\begin{array}{l}75,0 \\
73,2 \\
55,5 \\
55,9 \\
52,1 \\
49,0\end{array}$ \\
\hline
\end{tabular}

Таблица 3

Содержание легкоусвояемых растениями элементов в сухом веществе сапропелей Эстонской ССР

\begin{tabular}{|c|c|c|c|c|c|c|c|c|}
\hline \multirow{3}{*}{ Озеро } & \multicolumn{5}{|c|}{$M 2 / 100$ 己 } & \multicolumn{3}{|c|}{$M 2 / \kappa 2$} \\
\hline & \multirow[t]{2}{*}{$\mathrm{K}_{2} \mathrm{O}$} & \multirow[t]{2}{*}{$\mathrm{P}_{2} \mathrm{O}_{5}$} & \multirow[t]{2}{*}{$\mathrm{Ca}$} & \multirow[t]{2}{*}{$\mathrm{Mn}$} & \multirow[t]{2}{*}{$\mathrm{Fe}$} & $\begin{array}{c}1 \text { н. } \\
\mathrm{HCl}- \\
\text { вы- } \\
\text { тяжка } \\
\end{array}$ & \multicolumn{2}{|c|}{$\begin{array}{c}\mathrm{H}_{2} \mathrm{O} \text {-вы- } \\
\text { тяжка }\end{array}$} \\
\hline & & & & & & $\mathrm{Cu}$ & Mo & B \\
\hline $\begin{array}{l}\text { Элиствере } \\
\text { Моосте } \\
\text { Пяйдре } \\
\text { Пангоди } \\
\text { Вескиярв } \\
\text { Харку } \\
\text { Кахала }\end{array}$ & $\begin{array}{r}15,0 \\
3,8 \\
5,2 \\
5,5 \\
9,0 \\
19,0 \\
9,5\end{array}$ & $\begin{array}{r}3,6 \\
12,8 \\
4,5 \\
5,6 \\
3,4 \\
20,6 \\
4,2\end{array}$ & $\begin{array}{r}1379 \\
1895 \\
1905 \\
1121 \\
942 \\
228 \\
1657\end{array}$ & $\begin{array}{r}174,5 \\
138,4 \\
144,5 \\
78,2 \\
144,5 \\
66,2 \\
66,2\end{array}$ & $\begin{array}{c}93,5 \\
1313 \\
375 \\
37 \\
281 \\
28 \\
219\end{array}$ & $\begin{array}{l}4,4 \\
2,3 \\
3,6 \\
4,0 \\
3,6 \\
4,5 \\
-\end{array}$ & $\begin{array}{l}0,05 \\
0,15 \\
0,15 \\
0,05 \\
0,15 \\
0,13 \\
-\end{array}$ & $\begin{array}{l}1,10 \\
0,95 \\
0,75 \\
1,00 \\
1,08 \\
0,90 \\
0,30\end{array}$ \\
\hline
\end{tabular}

Таблица 4

Валовое содержание меди, кобальта и марганца в сухом веществе донных отложений малых озер Эстонии, мг/кг

\begin{tabular}{l|c|c|c|c|c}
\hline \multicolumn{1}{c|}{ Озеро } & Скважнна & $\begin{array}{c}\text { Глубина } \\
\text { взятя пробы. } \\
\mu\end{array}$ & Cu & Co & Mn \\
\hline Элиствере & 3 & $1,8-5,4$ & 12,4 & 7,8 & 278 \\
Моосте & 1 & $1,6-10,0$ & 11,2 & 11,5 & 356 \\
Кирикумяэ & 178 & $4,9-7,6$ & 12,1 & 13,0 & 318 \\
Кообассааре & 1 & $2,0-5,1$ & 9,7 & 12,4 & 438 \\
Пяйдре & 278 & $0,5-5,0$ & 17,2 & 12,4 & 454 \\
Пангди & 53 & $3,0-9,7$ & 15,4 & 12,1 & 366 \\
Мустъярв & 1 & $2,8-3,1$ & 11,8 & 16,0 & 210 \\
Руйла & 2 & $1,0-2,1$ & 18,1 & 11,3 & 246 \\
Кыверъярв & 4 & $0,7-2,7$ & 17,4 & 9,8 & 387 \\
Вескнярв & 1 & $1,0-2,7$ & 16,1 & 16,8 & 225 \\
Харку & $M_{2}$ & $1,5-2,2$ & 12,6 & 8,1 & 355 \\
Харку & $M_{2}$ & $2,2-3,2$ & 8,5 & 6,1 & 286
\end{tabular}

карбонатами, т. е. чем меньше степень насыщенности, тем меньше содержание карбонатов в сапропелях. На основе этого показателя изученные сапропели можно разделить на две группы: 1) сапропели со степенью насыщения $50-75 \%$ (оз. Вескиярв, Харку) и 2) сапропели со 
степенью насыщения 75-100\% (оз. Элиствере, Моосте, Пяйдре, Пангоди, Юлемисте, Кахала). Так как большинство изученных сапропелей имеет высокую степень насыщения, то они применимы в качестве органо-минеральных удобрений и для известкования кислых почв.

Состав сапропелей. Изученные сапропели во многих случаях содержат к а р бон а ты (табл. 1), иногда даже в виде прослоек озерной извести (Руйла, Элиствере, Рябиярв, Юузаярв). Бедные карбонатами сапропели встречаются в озерах, которые располагаются на камовых полях (Вийтна Сууръярв, Кыверъярв, Мустъярв) и в предглинтовой зоне (Харку), в местах распространения песчаных отложений.

Кальций присутствует в виде карбоната, сульфата, алюмосиликатов и в составе поглощенного комплекса. Роль кальция в агротехнике значительная, так как он благоприятствует образованию структуры почвы, коагулирует коллоиды, нейтрализует кислоты, способствует развитию микрофлоры, являясь в то же время незаменимым питательным элементом растений (Качинский, 1975). Из валового содержания кальция весьма важна лишь легкоусвояемая растениями часть, количество которой составляет от 200 до 1900 мг/100 г (табл. 3).

Среди легкоусвояемых растениями питательных элементов наиболее важную роль играют азот, калий, фосфор и ряд микроэлементов, из которых нами определены бор, медь и молибден (табл. 2, 3, 4).

Азот. Формы азотистых соединений в сапропелях разнообразны. Нами определены общий азот по Къельдалю и гидролизируемый азот. Для определения последнего 1 г воздушно-сухого сапропеля обливали 100 мл 0,1 н., 0,5 н., 1,0 н., 2,0 н. раствора $\mathrm{HCl}$ и нагревали в течение 3 чна водяной бане. В гидролизате определяли азот также по Къельдалю. Содержание общего азота колеблется в изученных сапропелях от 1,4 (оз. Пангоди) до $3,7 \%$ (оз. Кирикумяэ, Кообассааре). Содержание азота обычно увеличивается с увеличением содержания органического вещества (табл. 1). Это показывает, что изученные сапропели с высоким содержанием органического вещества являются потенциальными источниками азотистых веществ. Гидролизуемость азотсодержащих веществ при 0,1 н. $\mathrm{HCl}$ составляет примерно $25 \%$ общего количества его. При этом с увеличением концентрации $\mathrm{HCl}$ до 2,0 н. роль гидролизуемого азота увеличивается до $50-75 \%$. Гидролизуемость азотсодержащих веществ контролируется не общим содержанием азота и органического вещества (табл. 2), а степенью гумификации сапропелей (Вимба, 1976). На латвийских сапропелях доказано, что малогумифицированные сапропели гидролизуются лучше, чем гумифицированные.

Фосфор $\left(\mathrm{P}_{2} \mathrm{O}_{5}\right)$. Содержание легкоусвояемого растениями фосфора, определенного по Кирсанову, колеблется от 3,4 мг/100 г в сапропелях оз. Вескиярв до 20,6 мг/100 г в сапропелях оз. Харку. Если взять критерием оценки содержания $\mathrm{P}_{2} \mathrm{O}_{5}$ предложенную почвоведами степень обеспеченности (Аринушкина, 1961), то этот показатель высокий для сапропелей оз. Харку, а средний для сапропелей оз. Моосте $(12,8$ мг/100 2). Сапропели всех остальных озер содержат фосфора в количествах, не обеспечивающих жизнедеятельность растений.

$\mathrm{K}$ алй й $\left(\mathrm{K}_{2} \mathrm{O}\right)$ обнаружен в сапропелях в незначительных количествах, обычно 0,2-0,4\% (Вимба, 1976). При этом легкоусвояемая растениями часть, определенная по методике Эгнера-Рима, составляет 3,8-19,0 мг/100 г (табл. 3). Сапропели оз. Элиствере и Харку, содержащие калия 15,0 и 19,0 ма/100 д, обладают средней степенью обеспеченности сапропелей калием, все остальные - низкой. Значит, содер- 
жание легкоусвояемого растениями $\mathrm{K}_{2} \mathrm{O}$ и $\mathrm{P}_{2} \mathrm{O}_{5}$ в изученных сапропелях небольшое, за исключением озер Харку и Юлемисте. Последние располагаются в пределах г. Таллина и в течение многих веков находились под влиянием хозяйственной деятельности человека. Являются ли повышенные содержания калия и фосфора результатом загрязнения этих озер или своеобразной характерной чертой этих отложений, требует дальнейшего изучения.

Чтобы охарактеризовать степень усвояемости растениями микроэлементов, содержащихся в сапропелях, определено количество легкоусвояемых форм бора, меди и молибдена (табл. 3).

Бор (В) в сухом веществе сапропелей составляет 3-48 ма/кг (Саaрсе, 1976). Содержание легкоусвояемых форм бора в большинстве случаев составляет лишь $0,9-1,0$ мг/кг, что является недостаточным для нормальной жизнедеятельности растений.

Медь (Cu). Валовое содержание меди в сапропелях довольно высоко - от 9,7 мг/кг в сапропелях оз. Кообассааре до 18,1 мг/ка в сапропелях оз. Руйла (табл. 4). Содержание легкоусвояемой растениями меди уступает валовому в три-пять раз, составляя 2,3-4,5 мг/кг (табл. 3). Наиболее высокие значения легкоусвояемой меди установлены в сапропелях оз. Пангоди, Әлиствере и Харку (более 4,0 мг/кг), что считается достаточным для растений. В остальных изученных нами сапропелях содержание легкоусвояемой меди не достаточное для растений.

Молибден (Мо) играет важную роль в азотном обмене растений и микроорганизмов. Содержание подвижного Мо значительно меньше, чем содержание $\mathrm{Cu}$ и $\mathrm{B}$ (соответственно 0,05 и 0,15 мг/к2). Мо находится в тесной связи с его валовым содержанием, составляя 5-10\% общего запаса его (Вимба, 1976).

Изученные нами сапропели характеризуются различными агрохимическими свойствами. Последние контролируются многими факторами, прежде всего, реакцией сапропелей, содержанием органического вещества и карбонатов. Умеренное содержание карбонатов в сапропелях весьма положительно с агрохимической точки зрения, так как карбонаты нейтрализуют кислотность почвы и способствуют образованию структурных агрегатов почв. Однако бескарбонатные сапропели с высоким содержанием органического вещества обычно содержат сравнительно много азотистых соединений, являющихся исходным материалом для производства аминокислот и биологически активных веществ.

Исходя из агрохимических данных описанные выше озера и встречаемые в них сапропели можно разделить на три группы: 1) кислые малокарбонатные сапропели (оз. Вескиярв, Харку); 2) нейтральные или слабощелочные известковистые сапропели со средним содержанием органического вещества (Юлемисте, Руйла, Элиствере, Пяйдре, Юузаярв, Пангоди, Рябиярв, Моосте); 3) нейтральные бес- или малокарбонатные сапропели с повышенным содержанием органического вещества (Кахала, Вийтна Сууръярв, Мустъярв, Кыверъярв, Кообассааре, Кирикумяэ).

Озера первой группы располагаются в зоне, где распространяются подзолистые почвы (рисунок). Встречаемые здесь сапропели не пригодны в качестве удобрения в данном почвенном районе из-за кислотности и отсутствия карбонатов. Эти сапропели можно применять для улучшения малопродуктивных угодий добавкой извести на нейтральных или щелочных почвах.

2 ENSV TA Toimetised. G 11981 
Озера второй группы наиболее часты на Отепяской возвышенности. Накопленные в этих озерах сапропели пригодны в качестве удобрения на всех типах почв, особенно в южной Эстонии на дерново-подзолистых почвах.

Озера и сапропели третьей группы часто связаны с камами и озами. Сапропели этих озер обладают высоким содержанием органического вещества и, несмотря на неоднократное вымораживание, при окончательном высыхании из-за устарения коллоидов все же окаменеют. Поэтому эти сапропели не применимы в качестве удобрения без предварительной обработки. Так как сапропели этой группы содержат в значительном количестве азотистые вещества, то их можно рекомендовать для производства биологически активных веществ и аминокислот.

\title{
Л ИТ Е Р АТ У Р А
}

Агрохимические методы исследования почв. М., 1975.

А риннушкин а Е. В. Руководство по химическому анализу почв. М., 1961.

В о збудцк а я А. Е. Химия почвы. М., 1968.

В и м б а Б. Сапропель в сельском хозяйстве. - В кн.: Гумифицированные сырья Латвийской ССР. Рига, 1976, 66-102.

В и м б а Б., Анде р сон с И., Л а п с Э. Исследование химического состава и агрохимических свойств сапропелевых отложений озер Юлемисте, Кахала и Харку Эстонской ССР. - Тр. ЛСХА, 1978, 141, 18-25.

К а чи н с ки й Н. А. Почва, ее свойства и жизнь. М., 1975.

$\mathrm{C}$ a а р се Л. О составе сапропелевых отложений гляциальных озер Эстонии. - Изв. АН ЭССР. Хим. Геол., 1976, 25, 161-168.

$\mathrm{H}$ a $11 \mathrm{ik}$, O. Mullateaduse ja agrokeemia praktikum. Tartu, 1948.

Hallik, O. Happeliste muldade lupjamine Eesti NSV-s. Tln., 1965.

L i 11 e m a a, A. Eesti NSV mullastik. Tln., 1958.

Veber, K. Järvemuda söödaks ja väetiseks. - Rahva Hääl, 1967, 16. juuli.

V e ber, K. Mōningate Eesti järvede setted. - EMMTUI teaduslike tööde kogumik. XX. TIn., 1970, 226-237.

\author{
Ннститут геологии \\ Академии наук Эстонской ССР \\ Управление геологии Эстонской ССР \\ Латвийская сельскохозяйственная \\ академия
}

Поступила в редакцию

Leili SAARSE, B.VIMBA|, R. SINISALU,

D. TRUKSNE, V. SKELE ила в ред
3/VI 1980

\section{EESTI VÄIKEJÄRVEDE MUDA AGROKEEMILINE ISELOOMUSTUS}

Uuritud väikejärvede muda on happelise, neutraalse või nõrgalt aluselise reaktsiooniga. Muda koostis, eelkõige karbonaatsus ja orgaanilise aine sisaldus, varieeruvad suurtes piirides, mis tingib ka agrokeemiliste omaduste ja taimedele kergesti omastatavate mikrokomponentide muutlikkuse. Koostise ja agrokeemiliste omaduste alusel on mudad jaotatud kolme rühma. Rōhutatakse, et järvesetete kasutamisel põlluväetisena tuleb arvestada mitte ainult muda, vaid ka väetatava mulla omadusi. 
Leili SAARSE, $\overline{|B . V I M B A|}$, R. SINISALU,

D. TRUKSNE, V. SKELE

\section{AGROCHEMICAL CHARACTERIZATION OF ORGANIC LAKE DEPOSITS OF SMALL LAKES IN ESTONIA}

This paper deals with investigation results of organic lake deposits of small lakes in Estonia situated in various soil regions. The examined deposits show acidic, neutral or slightly alkaline reaction. They consist mainly of organic matter $(30-90 \%)$, the amount of calcium carbonate $\left(\mathrm{CaCO}_{3}\right)$ being up to $30 \%$. The average content of nitrogen is up to $3.7 \%$ in deposits with a high value of organic matter. The amount of exchangeable phosphorus $\left(\mathrm{P}_{2} \mathrm{O}_{5}\right)$ attains $21 \mathrm{mg} / 100 \mathrm{~g}$, and that of potassium $\left(\mathrm{K}_{2} \mathrm{O}\right)$ $19 \mathrm{mg} / 100 \mathrm{~g}$. The content of trace elements (Cu, Mo, B) is low. On the basis of agrochemical data it has been stated that the organic lake deposits from small lakes in Estonia are characterized by various properties that depend on their carbonate content and organic matter amount as well as acidity. The authors distinguish three groups of organic lake deposits, suggesting that they might be used as fertilizers of soils, and for producing amino acids and biologically active substances. 